\title{
Tritium Diagnostics by Balmer-alpha Emission
}

\author{
C H Skinner, A T Ramsey, D W Johnson and M Diesso. \\ PPEL--2878 \\ DE93 007934 \\ Plasma Physics Laboratory \\ Princeton University.
}

\begin{abstract}
Spectral line emission from tritium in a plasma may be distinguished from deuterium emission by a small isotope shift. A diagnostic system to measure tritium Balmer-alpha emission from the plasma edge has been installed on TFTR. This system has been used in deuterium plasmas, and the deuterium alpha line profile used as a basis to predict the spectrum at differing tritium concentrations in future D-T runs. The tritium and deuterium lines are partially blended, however, analysis of the predicted D-T spectra by a line fitting program produced estimates of the tritium density that closely matched those input to the spectra, providing confidence that the tritium density can be reliably measured. The spectrum maps the tritium velocity distribution at the plasma edge and will be important for studies of tritium edge physics.
\end{abstract}




\section{INTRODUCTION}

Magnetically confined fusion stands at the threshold of producing significant fusion power by the introduction of the radioactive fuel, tritium, into the plasma. First discharges in deuterium-tritium fuelled mixtures have been reported from JET ${ }^{1}$ and tritium experiments in TFTR are planned for late 1993. 2 The fusion reaction rate is a maximum for equal densities of tritium ard deuterium, however methods to measure directly the tritium concentration in the plasma are rare. On TFTR, a diagnostic system has been installed to measure optical emission from the $6560 \AA n=3$ - $m=2$ Balmer-alpha transition in neutral tritium $(T \alpha)$, generated at the plasma edge. This emission, together with emission from deuterium alpha $(\mathrm{D} \alpha)$, and hydrogen alpha $(\mathrm{H} \alpha)$, occurs in the scrapeoff region when molecular hydrogen isotopes, recycled from the wall, undergo various electron impact dissociation reactions. ${ }^{3}$ Additional contributions to $\mathrm{T} \alpha, \mathrm{D} \alpha$, and $\mathrm{H} \alpha$ arise from charge-exchange neutrals and fast reflected particles. These lines are close in wavelength and will be partially blended. This paper reports on initial measurements of the $H \alpha, D \alpha$ line profile in TFTR and predictions, based on the experimental results, of the $H \alpha, D \alpha, T \alpha$ spectrum expected when tritium is added to the plasma. The predicted $H \alpha, D \alpha$, $T \alpha$ spectra was analysed to determine the feasibility of tritium density measurements from the Balmeralpha spectra.

Measurements of $\mathrm{H} \alpha$ and $\mathrm{D} \alpha$ emission have long been used in studies of the plasma edge. ${ }^{4-8}$ On TFTR a modular, fiberoptic coupled spectroscopic diagnostic (dubbed HAIFA ${ }^{9}$ ) is used to monitor the combined $\mathrm{D} \alpha, \mathrm{H} \alpha$ emission yielding information on core recycling rates, ion and neutral particle limiter fluxes and conditions in the plasma scrapeoff layer. ${ }^{10}$ This region is critically important since it permits the creation of "supershots" 11 and affects the heat and particle flux to the first wall, thereby controlling the tritium inventory accumulating in the machine. Hydrogen recycling from limiter or divertor targets plays a critical role in many aspects of plasma physics and engineering. The $\mathrm{D} \alpha, \mathrm{H} \alpha$ spectral line profile maps the velocity distribution of the atoms in the scrapeoff layer. Previous measurements of the $D \alpha, H \alpha$ line profile on TEXTOR ${ }^{12}$ revealed evidence for emission from fast ions that were neutralized and reflected at the limiter surface. This data was used to assess the existing database for hydrogen reflection and penetration into plasmas, ${ }^{13}$ important in modelling both current and future machines.

\section{EXPERIMENTAL SETUP}

The wavelengths of the $\mathrm{H} \alpha / \mathrm{D} \alpha / \mathrm{T} \alpha$ emission lines are separated by a small isotope shift arising from differences in the reduced mass and are at $6562.8 \AA, 6561.04 \AA$ and $6560.45 \AA$ respectively. Note that the $\mathrm{D} \alpha-\mathrm{T} \alpha$ separation $(1 / 3$ that of $\mathrm{D} \alpha-\mathrm{H} \alpha)$ is comparable to the linewidth so it is not clear a priori 
that T $\alpha$ can be measured independently. The fine strucnure splitting of $0.1 \AA$ is not resolved. A high resolution interferometer was installed to measure the spectrum on TFTR. The system is an upgrade of HAIFA, 9 an array of telescopes coupled by fiberoptics to a remote system of interference filters and detectors that is used for monitoring $\mathrm{H} \alpha, \mathrm{D} \alpha$ and visible bremsstrahlung emission. The bandpass of the filters is $10 \AA$ so the existing system measures the sum of the emission from the hydrogen isotopes. To resolve the individual spectral lines, the light emerging from the filter in a dedicated HAIFA channel was input to a Fabry Perot interferometer (Burleigh Model TL38). The setup is shown in figure 1 . The free spectral range of the Fabry Perot was $7 \AA$ and plate reflectivity $92 \%$ yielding a resolution of $0.2 \AA$.

The Fabry Perot repetitively scans the wavelength region. The minimum time to acquire a spectrum is $20 \mathrm{msec}$ (corresponding to 5 interference orders scanned in $100 \mathrm{msec}$ ). For the data presented here a slower scan speed ( 2 orders $500 \mathrm{msec}$ ) was used to increase the signal/noise. The light was detected by a photomultiplier, amplified and digitized at $2 \mathrm{Khz}$. To maintain high resolution the drift in alignment of the interferometer plates must be less than $50 \AA$. Since access to the interferometer was not possible during machine operations, the interferometer was housed in a chamber in which the temperature was held constant to within $1^{\circ} \mathrm{C}$. In addition, an active stavilization system used an attenuated helium-neon laser beam that was input to the interferometer in the same fiber optic used for the plasma light. For the period 0-7 seconds during a plasma shot, this beam was blocked; at other times the signal from the laser was used in an electronic controller which maintained optimal Fabry Perot cavity separation. Since the line profile is scanned in time there is some potential for time dependent fluctuations in the edge density to modulate the line profile. A second HAIFA channel with a $10 \AA$ bandpass interference filter recorded the combined $H \alpha+D \alpha+T \alpha$ signal and was available to normalize the line profile where necessary.

Both telescopes viewed a region on the TFTR inner limiter $5 \mathrm{~cm}$ in diameter, $55 \mathrm{~cm}$ below the midplane. In this location the magnetic field strength was typically $6.5 \cdot 6.8$ Tesla in a direction $4^{\circ}$ below horizontal. The Zeeman effect splits the $H \alpha, D \alpha, T \alpha$ lines into an unshifted $\pi$ component, polarized parallel to the field direction, and two $\sigma$ components displaced by $\pm 1.3 \AA$ and polarized perpendicular to the field. The Zeeman splitting has been used to measure the local magnetic field and hence the location of the emission region. ${ }^{14}$ In the present experiment a polarizing filter was placed in front of the telescope lens and oriented to transmit only the unshifted $\pi$ component.

\section{RESULTS FROM DEUTERIUM, HYDROGEN PLASMAS}

The system was operational during the 10/92 - 11/92, run period and figure 2 shows a $H \alpha, D \alpha$ line profile taken during neutral beam injection at 3.7 seconds on shot 69019 . This was a 'supershot'11 
conditioned by the injection of 2 lithium pellets at $2 \mathrm{sec}$. The profile was taken in a single scan and it was not necessary to normalize it with the dita from the reference channel. An instrumental profile was taken immediately after the discharge using the helium-neon laser light and a dedicated linefitting program (SV.FOFFE) was used to analyze the data by the method of least squares. First, the instrumental profile was fit by a combination of 2 Gaussians with a 1st order polynomial background and then this was deconvolved from the observed $\mathrm{H} \alpha, \mathrm{D} \alpha$ profile. The resulting profile was analyzed by performing an unweighted least-squares fit to 4 Gaussian line profiles ( 2 for $\mathrm{H}$ and 2 for D), broadly corresponding to the contributions from 'cold' dissociation products and 'warm' chargeexchange atoms. ${ }^{7}$ The actual line profile is Doppler broadened and non-Maxwellian but could be well fit by the combination of 2 Gaussians per isotope. The resulting Gaissians, for deuterium had temperatures of $1 \mathrm{eV}$ and $24 \mathrm{eV}$ with the broad $24 \mathrm{eV}$ Gaussian slightly displacer: io shorter wavelengths by $0.25 \AA$. This displarement is attributed to the contribution of ions neutralized and reflected from the wall which have an anisotropic velocity distribution. From the fitting parameters the density ratio $H$ / $(H+D)$ in the scrapeoff region was determined to be $12 \%( \pm 3 \%)$. More significant for the planned $T \alpha$ measurements is the intensity of the line wings that determines the degree of blending of the $D \alpha$ and $T \alpha$ lines.

\section{TRITIUM ALPHA LINE PROFILE MODELLING}

The measured $H \alpha, D \alpha$ spectrai line profiles were used to provide a prediction of the spectrum expected when tritium is introduced into TFTR. No measurements of the $T \alpha$ line profile in a high temperature plasma have been made to date, however it it possible to make reasonable predictions of the expected profile based on the $D \alpha$ results. The kinetic energies of the excited tritium produced from dissociation and charge exchange are expected to be the broadly the same as deuteriun. There are some differences in the deuterium and tritium particle reflection coefficients in the datrbase used in the DEGAS ${ }^{15}$ code that will affect that part of the line profile arising from ions reflected and neutralized at the wall. These will be investigated when the experimental tritium line profile becomes available. For the present pusposes the major difference in the profile arises from the higher reduced mass that displaces the line center and decreases the Doppler width by a factor of $\sqrt{ }(3 / 2)$ compared to deuterium.

A "synthetic" tritium spectrum was constructed from the right hand side of the D $\alpha$ profile by manipulating the data elements with a spreadsheet program. After mirror reflection to generate a symmetrical profile, the line width was reduced by a factor 0.71 by deleting approximately every 5 th data element. The profile was then shifted in wavelength by the isotope shift, multiplied by a scaling factor corresponding to various tritium densities and added to the original data. The resulting $H, D, T$ predicted spectra are shown in Fig. 3. The T $\alpha$ and $\mathrm{D} \alpha$ line peaks are seer to be separated while the line wings are blended. 
These profiles were used as a test case to determine the accuracy of the linefit program in assessing the tritium level. The linefit program was used to fit the modified data with 2 Gaussians being allocated to each isotope (a total of 6 Gaussians) with a first order polynomial background. While the amplitudes of all the Gaussians were free, the total number of free parameters in the fit was reduced from 20 to 8 by linking the wavelengths and widths of the $T$ and $H$ profiles to the $D$ profile according to their known relation to the $\mathrm{D}$ parameters. The tritium / deuterium density ratios were calculated from the fitting parameters and the result compared to the input scaling factor. Preliminary results showed good agreement even for the lowest density case (see Fig. 4).

A second method was used to create a tritium profile. Here the Gaussian fitting parameters derived from the deuterium spectrum were modified to correspond to tritium, and a 2 Gaussian tritium profile generated. This was combined with the deuterium and hydrogen Gaussians and reconvolved with the instrumental profile. These resulting spectral profiles were consistent with those above.

The experimental spectral profile reflects the velocity distribution of hydrogen isotopes in the edge region. This parameter is also contained in recycling codes such as DEGAS that are used in divertor/edge studies of future machines, e.g., ITER. We plan to make a detailed comparison of the experimental profiles to the code predictions. This study will be a valuable benchmark of the code and lead to information on the physics of the edge region. We are also planning to improve the resolution and sensitivity of the experimental system to facilitate measurements at higher scan rates and lower light levels.

In summary we have installed a high resolution spectrometer and measured the $H \alpha, D \alpha$, line profile on TFTR. The profile has been used to predict that expected when tritium is added to the machine. The $H \alpha, D \alpha$ and $T \alpha$ lines emitted from the plasma edge will be partially blended, however analysis with line fitting software gives us confidence that it will be possible to measure reliably the tritium / deuterium density ratio and to investigate tritium edge physics.

\section{Acknowledgment}

We would like to acknowledge the support of the TFTR team and especially M Bell for the calculations of the magnetic field. The technical assistance of J Bartolick and P Sichta and J Nicolls for the interface of the electronics with the TFTR control and data acquisition system and G Drodz for mechanical construction are highly appreciated. We thank $D$ Stotler for providing information on the DEGAS code. This work was supported by the U.S. Department of Energy Contract No. DE-AC0276-CH03073. 


\section{Figure Captions}

Figure 1. Experimental setup.

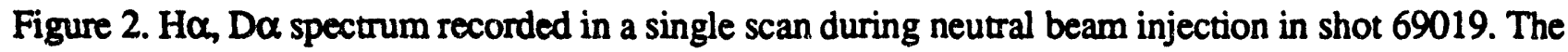
direction of scan is such that the wavelength decreases with increasing time.

Figure 3. Predicted profiles of $\mathrm{H} \alpha, \mathrm{D} \alpha$, and $\mathrm{T} \alpha$ at differing ratios of tritium to deuterikm density. The tritium peak for $T / D=0.71$ is more prominent than deuterium even though its density is lower, due to its narrower linewidth.

Fig. 4 The deviations from the straight line represent the difference between the T/D density ratio calculated from the line fitting parameters and tritium scaling factor used to create the line profile. 


\section{References}

1 P H Rebut, A Gibson, M Huguet et al. Nucl. Fusion 32, 187 (1992).

2 R J Hawryluk, D Mueller, J Hosea et al. Fusion Technology, 21, 1324 (1992).

3 D McNeil, J. Vac. Sci. Technol. A2, 689, 1984).

4 J G Hirschberg, J. Chem Phys., 45, 2233 (1966).

5 P Platz, 9th European Conference on Controlled Fusion and Plasma Physics, p154 (1979).

6 D E Post and R Behrisch, Physics of Plasma Wall Interactions in Controlled Fusion, Plenum Press (1986).

7 D H McNeil, J. Nucl Mater. 162, 476 (1989).

8 J T Hogan, C C Klepper, D L Hillis and T Uckan, J. Nuci. Mater., 162, 469 (1989).

9 A T Ramsey and S L Turner, Rev. Sci. Instrumen, 58, 1211 (1987).

10 D H Heifitz, A B Ehrhardt, A T Ramsey, H F Dylla, R Budny, D McNeil, S Medley and M Ulrickson, J. Vac, Sci, Technol, A6, 2564 (1988).

11 J D Strachan, M D Bitter, A T Ramsey, et al., Phys. Rev. Lett. 58, 1004, (1987)

12 U Samm P Bogen, H Hartig et al. J. Nucl. Mater. 162, 24 (1989).

13 D.Reiter, P.Bogen, U.Samm, J. Nucl. Mater. 191-194 (1992), in press

14 P G Carolan, M J Forrest, N J Peacock, and D L Trotman, Plasma Physics and Controlled Fusion, 27, 1101 (1985).

15 D H Heifitz et al., J. Comput. Phys. 46, 309 (1982). 


\section{PPPL\#93X0001}

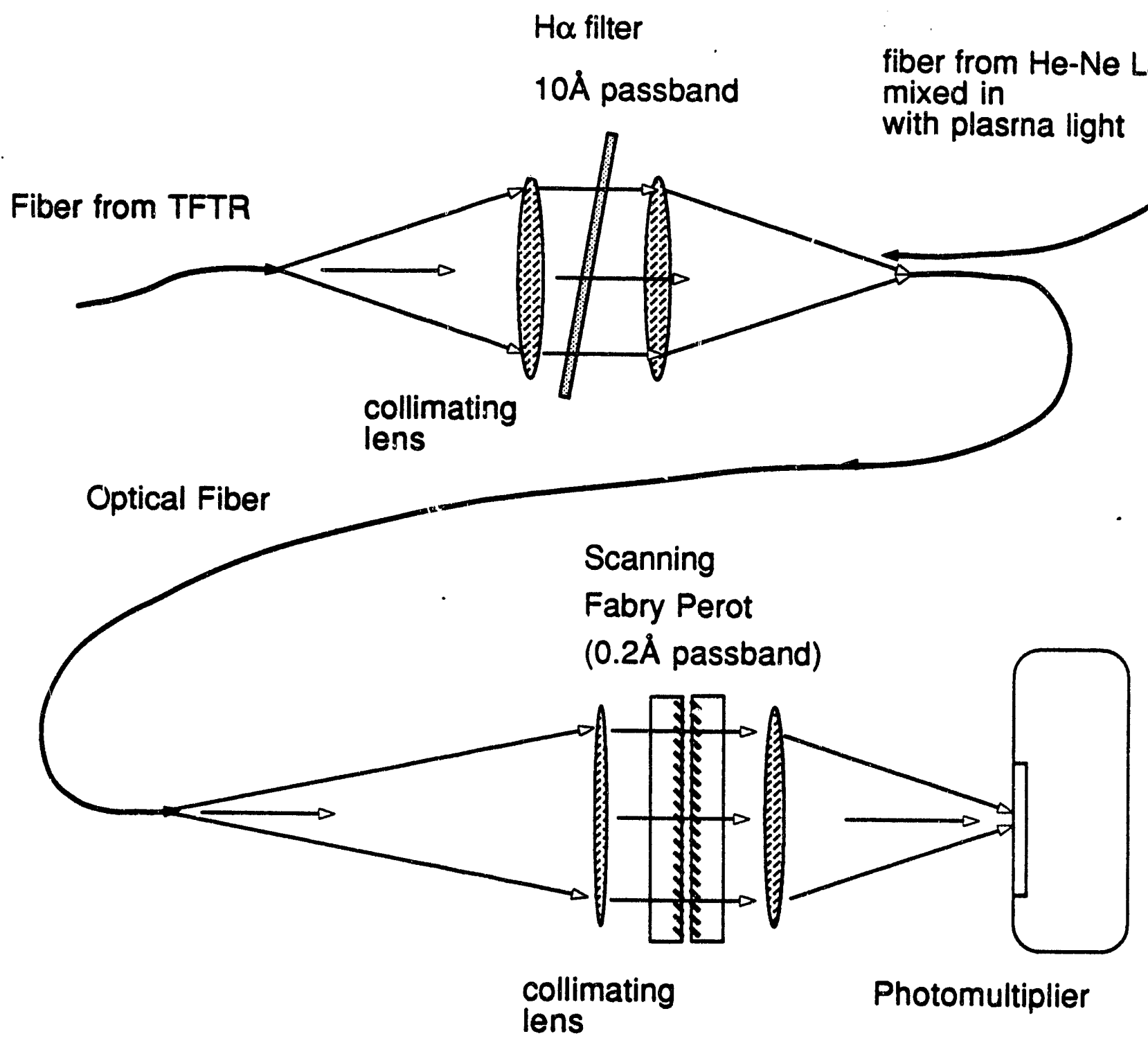

Fig. 1 
PPPL\#93X0002

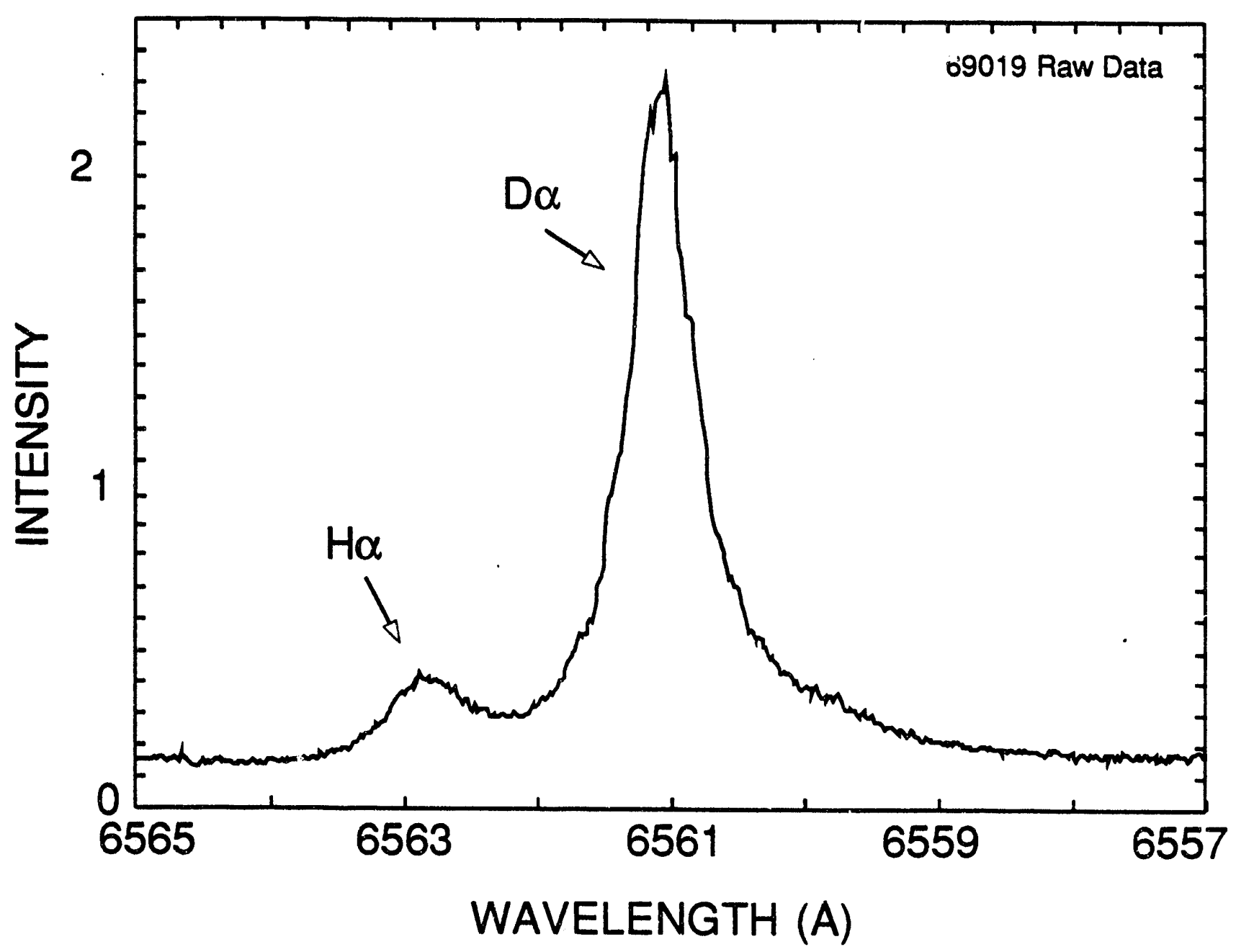

Fig. 2 
PPPL\#93X0003

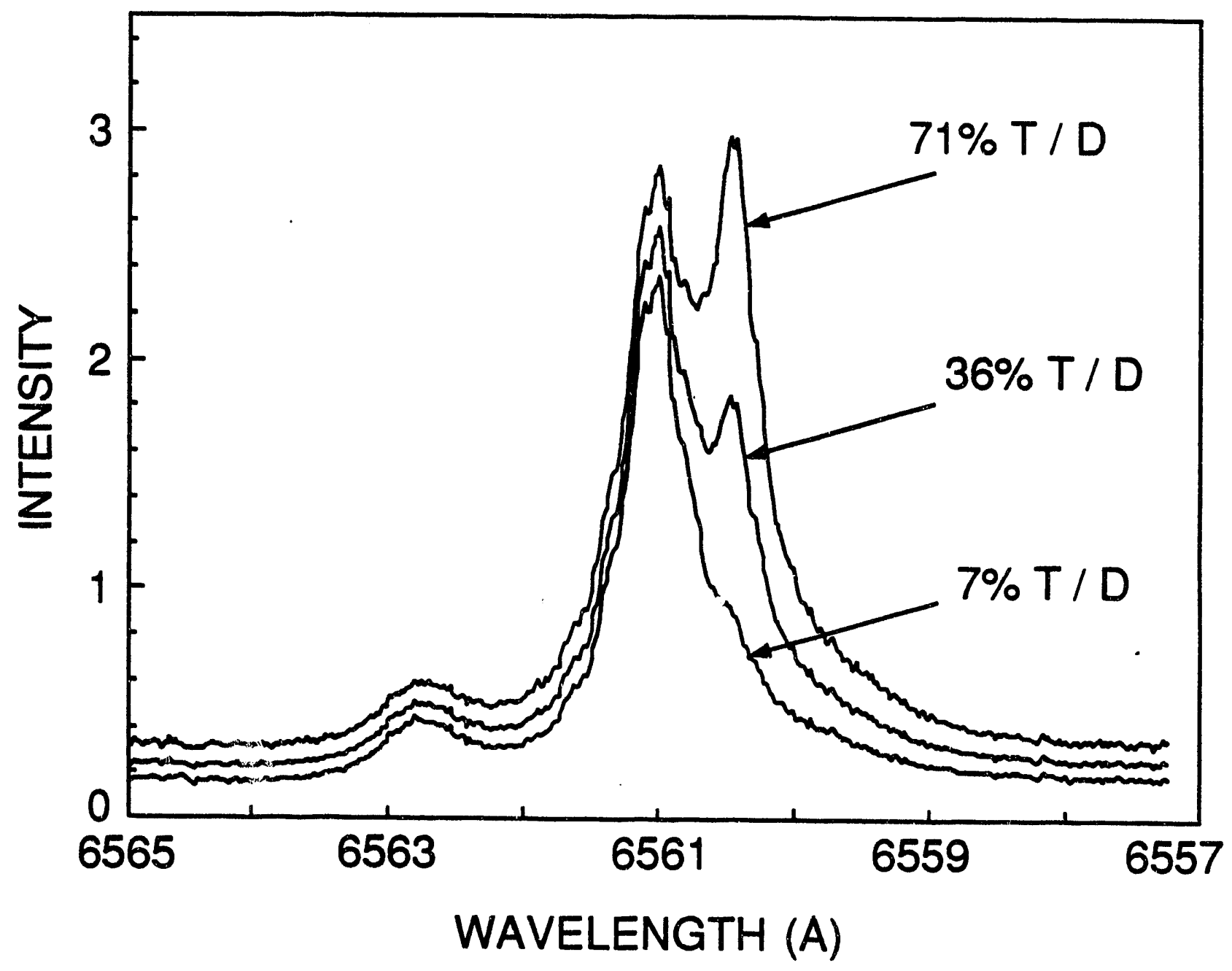

Fig. 3 


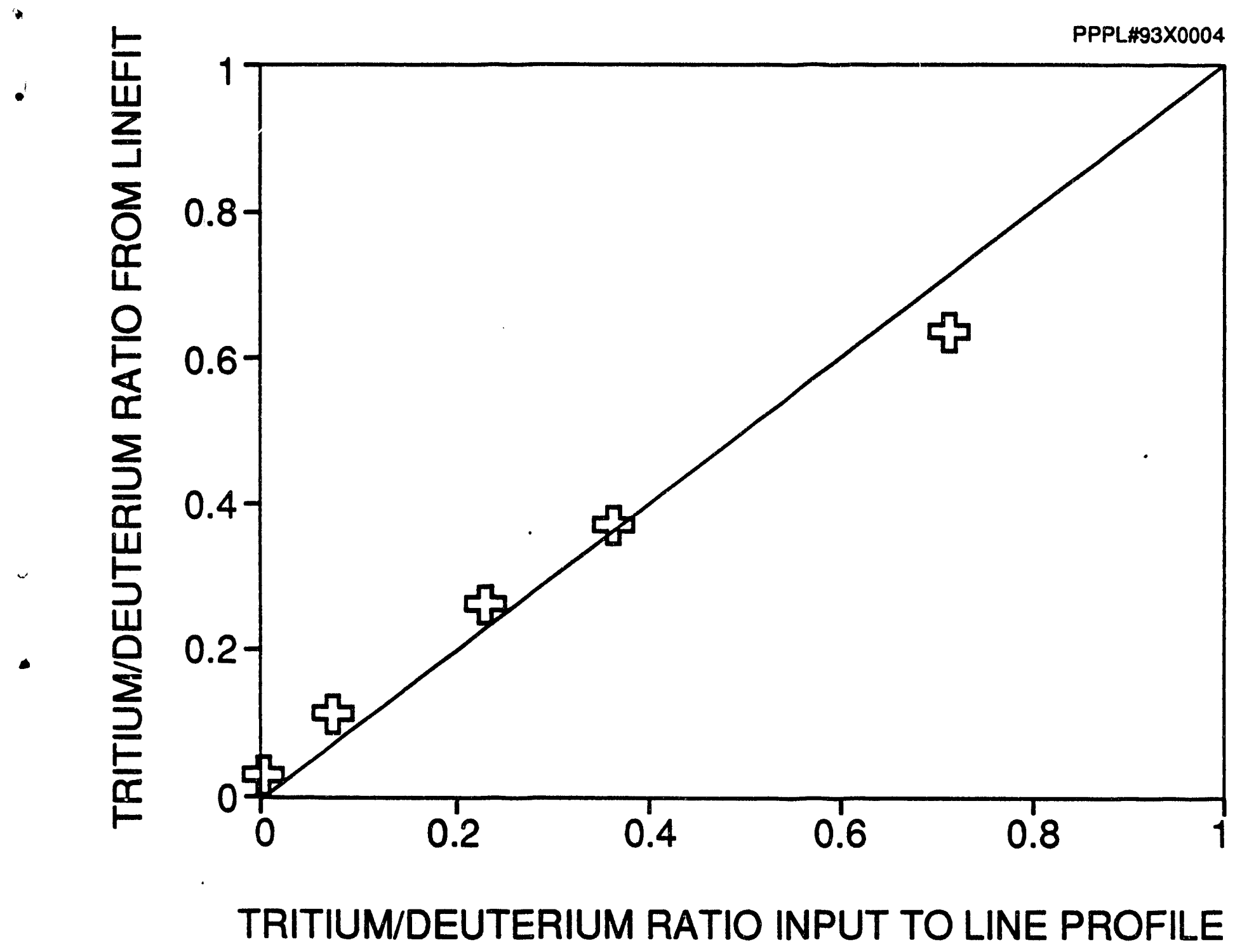

Fig. 4 
EXTERNAL DISTRIBUTION IN ADDITION TO UC-420

Dr. F. Peotoni, Univ. of Wollongong. AUSTRaLIA

Prof. M.H. Brennan, Univ. of Sydnoy, AUSTRuLlA

Plesma Research Lob., Australien Nat Univ., AUSTRALIA

Prof. I.R. Jones, Flindors Univ, AUSTRALLA

Prot. F. Cep, Inat for Theoretical Phyeics, AUSTRIA

Prof. M. Hoindiser, Instrut for Thecretiecthe Physik, AUSTRIA

Prot. M. Goosesns, Astronomicch InetituUt, BELCIUM

Ecole Royda Mituiro, Lob. de Phy. Plasmas, BELeIUM

Commicaion-European. DG. XIHFUaion Prog., BELCIUM

Prot. R. Bouciqus, Rikeuniveribit Gent BELCIUM

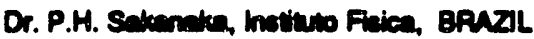

Inatituto Neciond De Pesquieas Eapacicie-INPE, BRAZIL

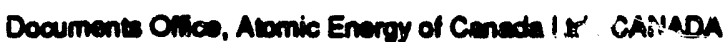

Dr. M.P. Bechynaki, MPB Technolocios, Inc., 1 . \%

Dr. H.M. Skeregand, Univ. of Seakatchowen, CANAOA

Prof. J. Teichmem, Univ. of Montreed, CANAOA

Prot. S.R. Sremivenen, Univ. of Cedoay, CANADA

Prof. T.W. Johneson, INASEneroio, CANADA

Dr. R. Bowon, Centre canedien do hueion magnetique, CAMADA

Dr. C.R. Jemes.. Univ. of Aberte, CAMADA

Dr. P. Luktic, Komenakcho Univeratita, CZECHO-SLOVAKIA

Tho Librarian, Culnam Luboralong, ENCLAND

Librery, PB1, Ruthertord Applaton Leboretory, ENGLAND

Mrs. S.A. Hutchinseon, JET Library, ENGLAND

Dr. S.C. Shema, Univ. of South Pecific, FWI ISLANDS

P. Mroinen, Univ. of Hodeindi, FINLAND

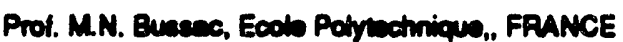

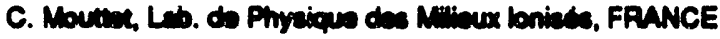

J. Radu, CENCAOARACHE - Bat 506, FRANCE

Prof. E. Economou, Univ. of Cres, GREECE

Mu. C. Rinni, Univ. of lomina, CAEECE

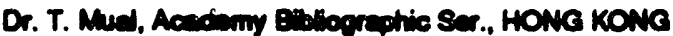

Preprink Library, Hungarien Acudoriny of SCi. HUNCAPY

Dr. B. Descepta, Saha Inat of Nuctare Phyrics, MDIA

Dr. P. Kan, Inet. for Pleuma Paesearch, INDLA

Dr. P. Roeseney, lead inst of Technobog, ISRAEL

Librevien, Intemationel Conter for Theo Phyeice, ITALY

Mies C. De Pab, Associarions EURATOM-ENEA, ITALY

Dr. G. Groseo, Isoiuto d Fisica del Plasma, ITALY

Prof. G. Rostengni, Istitus Gas lonizzed Del Cnr, ITALY

Dr. H. Yenewo, Toshibe Res Dovel Conter, JAPAN
Prof. I. Kawakemi, Hiroshima Uniry., LAPAN

Prof. K. Niehikema, Hroshim Univ., JAPAN

Director, Jepen Atomic Energy Rosearch Inst, JAPAN

Prot. S. Itoh, Kyuahu Univ., JAPAN

Rasedech info. Cr., Nationd Instit. for Fusion Scienco, JAPAN

Prof. S. Tendka, Kyow Univ., JAPAN

Librery, Kyoto Univ., JAPAN

Prot. N. Inowe, Univ. of Tolyyo, LAPAN

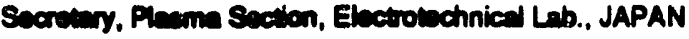

S. Movi, Techniced Advicor, LAEPR, LAPAN

Dr. O. Mind, Kumenow lnet of Tectnology. JAPAN

J. Hyeon-Sook, Konsa Atomic Energy Rosearch Inst, KOAEA

D.I. Chai, Tho Korea Adv. hat of Sai. a Tech., KOAEA

Prof. B.S. Liby. Univ. of Weikato, NEW ZEALAND

Int of Phyrica, Chinese Acad SaI PEOPLE'S REP. OF CHINA Librey. Inte of Plaema Phycica, PEOPLE'S REP. OF CHINA

Tainghua Univ. Librey, PEOPLES REPUBUC OF CHINA

Z. U. S.W. hat Phycica, PEOPLE'S REPUBLIC OF CHINA

Prot. J.A.C. Cebrd, instuto Superior Tecnico, PORTUGAL

Dr. O. Potus, Al I Cuza Univ., ROMurila

Dr. J. de Vivien, Fusion Studies, AEC, S. AFPICA

Prot. MA. Hemberg, Univ. of Natel, S. AfRiCA

Prof. D.E. Km, Poheng Inst. of Sci. \& Tech., SO. KOREA

Prof. C.I.E.MA.T, Fuion Division Library, SPAIN

Dr. L SWmib, Univ. of UMEA, SWEDEN

Librey, Royd Inet of Technolooy, SWEDEN

Prof. H. Wirtemeon, Chamere Univ. of Tech., SWEDEN

Corrue Phys. Des Plasmas, Ecolo Potysech, SWITZERLAND

Bubliburate, lnat. Voor Plasma-Fyeica, THE NETHERLANDS

Alet Prof. Dr. S. Cekir, Mid beat Tech. Univ., TUAKEY

D. V.A. Chuthinh,Sal. Ras. hat Encusophys.I Apperesus, USSR

Dr. D.D. Ryutov, Siburian Buench of Acadermy of Sai., USSR

Dr. G.A. Evimow, I.V. Kuncha wou Inet, USSA

Libreien, Tho Ukr.SSR Acadimy of Sciences, USSA

Dr. LM. Kowrizhnyth, lnet. of Gimeral Phyrics, USSA

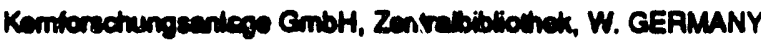
Biblictuck, Inst. For Phamabrecturnt W. GERMANY

Prof. K. Schindiox, Puhr-Univeraitu Bochum, W. GERMANY

Or. F. Wegner. (ASDEX), Max-Ptenck-Institut, W. GERMANY

Librerien, Max-Plenck-Instiut, W. GERMANY

Prot. R.K. Jenev, Inat of Physica, Yucosuavia 


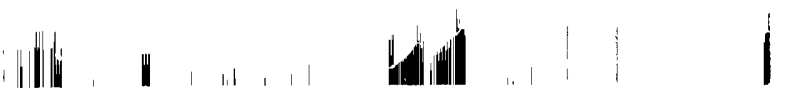
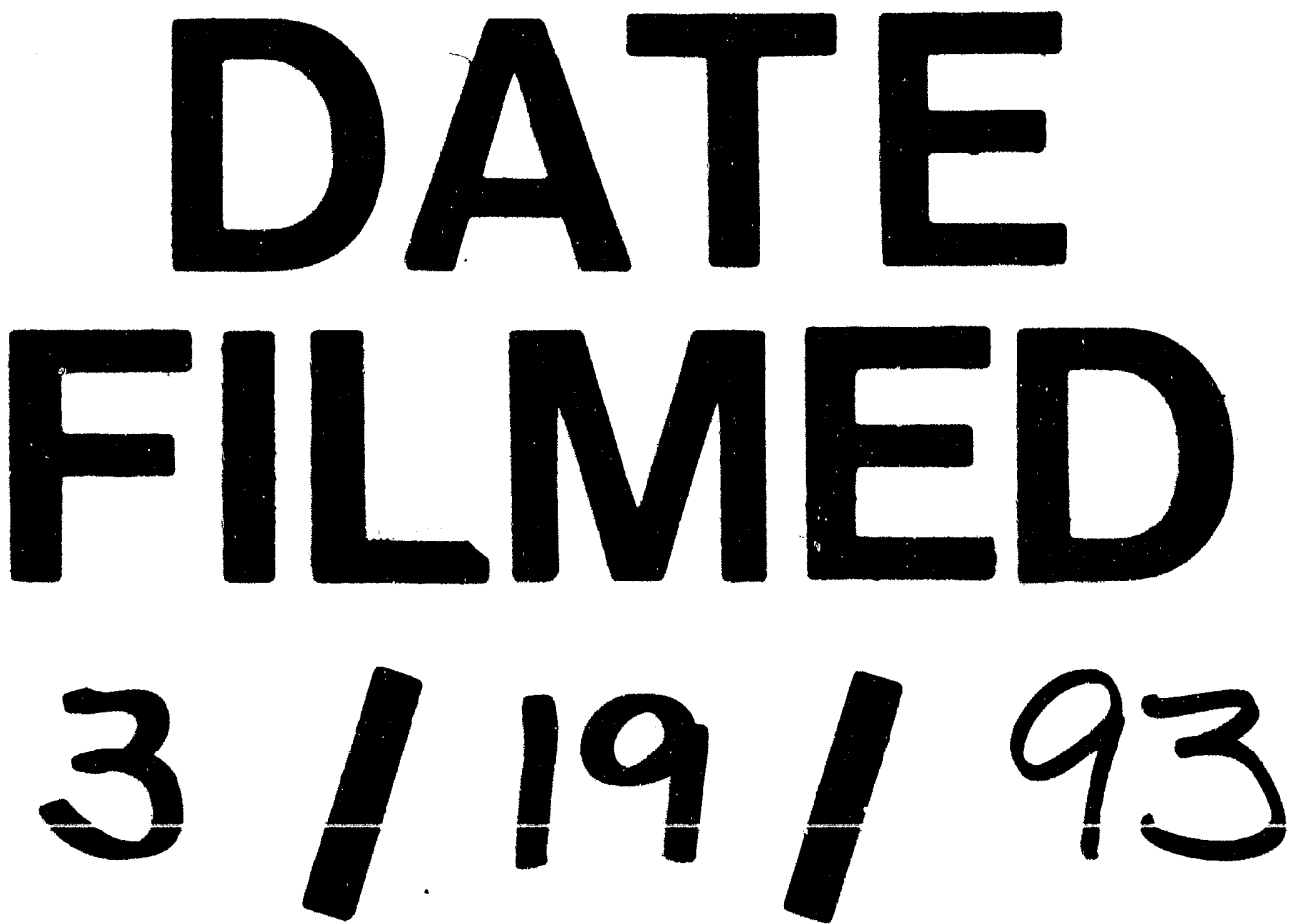
